\title{
Influence of decelerating flow on incipient motion of a gravel-bed stream
}

\author{
HOSSEIN AFZALIMHR*,1, SUBHASISH DEY ${ }^{2}$ and \\ POONEH RASOULIANFAR ${ }^{1}$
}

${ }^{1}$ Department of Water Engineering, Isfahan University of Technology, Isfahan, Iran

${ }^{2}$ Department of Civil Engineering, Indian Institute of Technology,

Kharagpur 721302

*e-mail: hafzali@cc.iut.ac.ir

MS received 4 June 2006; revised 18 April 2007

\begin{abstract}
An experimental study on incipient motion of gravel-bed streams under steady-decelerating flow is presented. Experiments were carried out in a flume with two median grain sizes, $d_{50}=16.7 \mathrm{~mm}$ for a fixed-bed case and $d_{50}=8 \mathrm{~mm}$ for a mobile bed case. In addition, an effort is made to determine a simplified method for the estimation of bed shear stress in decelerating flow over fixed and mobile beds for use in field situations. From the observation of eleven fixed-bed and nine mobile-bed velocity profiles, it is revealed that the parabolic law method (PLM) and the Reynolds stress method are comparable for estimation of shear velocity in general. Also, the results show that the shear stress distribution adopts a convex form over fixed and mobile beds. Due to this form the critical Shields parameter value for decelerating flow is less than the reported values in literature.

This paper supports Buffington \& Montgomery (1997) statement that less emphasis should be given on choosing a universal shields parameter, and more emphasis should be given on choosing defendable values based on flow structure.
\end{abstract}

Keywords. Incipient motion; gravel-bed; decelerating flow; Shields parameter; parabolic law.

\section{Introduction}

The movement of sediment along a channel has been the most challenging problem to hydraulicians. Incipient motion of the bed sediment refers to the beginning of movement of bed particles. There are some difficulties in defining the incipient conditions precisely. The accurate measurement of water discharge in a channel at which the incipient motion occurs is a subjective criterion. In addition, the difficulty of observing sediment particles at the initiation of motion is another reason for the lack of general definition of incipient motion. Incipient motion of stream-beds is a fundamental aspect of river mechanics that has applications to a wide variety of research problems, such as stable channel design, scouring of river-beds, etc. Usually most investigators use a standard or modified form of the critical Shields parameter 
$\left(\tau_{* c}\right)$ to define incipient motion of a given sediment size. The Shields parameter or dimensionless shear stress is defined as $\tau_{*}=\tau /\left[\left(\gamma_{s}-\gamma\right) d_{50}\right]$, where $\tau$ is the bed shear stress, $d_{50}$ is the median diameter of sediment particles; and $\gamma_{s}$ and $\gamma$ are the specific weights of sediment and water, respectively.

Shields (1936) showed that $\tau_{* c}$ for uniform sediments varies with critical particle Reynolds number $\mathrm{Re}_{* c}$ and that attains a constant value of 0.06 for $\mathrm{Re}_{*}>500$. The critical particle Reynolds number is defined as $\operatorname{Re}_{* c}=u_{* c} k_{s} / \nu$, where $u_{* c}$ is critical shear velocity for incipient motion, that is $\left(\tau_{c} / \rho\right)^{0 \cdot 5} ; \rho$ is the mass density of water; $k_{s}$ is the Nikuradse's equivalent roughness, being assumed to be $d_{50}$; and $v$ is kinematic viscosity. Several investigators (Garde \& Ranga Raju 1985, Buffington \& Montgomery 1997, Wilcock 1988, 1992 and Lavelle \& Mofjeld 1987) analysed data on critical shear stress. They showed that the divergence between various methods and departure of experimental data from these. They stated that one reason of scatter in various studies is the definition of critical condition employed by different investigators. Also, the other reason of divergence is the fact that each investigator carried out his experiments in a limited range of sediment size. Also,when the material is nonuniform, it is extremely difficult to define the condition of incipient motion. In this condition the coarse particles would move relatively easily and the smaller ones move less readily because they will be sheltered. (Garde \& Ranga Raju 1985). Therefore, it is important to find out the representative grain size in a mixture for critical condition. Likewise, it is interesting to know whether the critical shear stress calculated in this manner is smaller or larger than the critical shear force for uniform material of the same grain size. Aki and Sato (see Iwagaki 1956) showed that critical shear stress for non-uniform material will be smaller than the critical shear stress for uniform material of the same median size.

There have been number of additions and modifications on the shields curve in later period. Limited experiments by Fernandez Luque \& Van Beek (1976) and Ikeda (1982) showed that the critical shear stress required for the initial movement of sediment on a stream-wise sloping bed decreases with increasing in slope. Using a larger data set, Yalin \& Karahan (1979) reported that $\tau_{* c}$ is 0.045 for rough turbulent flow, and it was in conformity to the finding of Miller et al (1977), who compiled flume data from various sources. Song \& Graf (1994) carried out research on the effect of uniform flow in open channels with movable gravel-bed. Dey (1999) put forward a theoretical model for the threshold of sediment motion on streamwise sloping beds considering the equilibrium of a solitary sediment particle. Furthermore, experimental studies with gravel-beds were put forward by Mizuyama 1977, Bathurst et al 1987, Andrews \& Parker (1987), Wiberg \& Smith 1987, Andrews (1994), Chiew \& Parker 1994, Church et al 1998, Patel \& Ranga Raju 1999, Dey \& Debnath 2000, Dey \& Raju (2002) and Mueller et al 2005.

Over the eight decades, the incipient of motion of uniform flow have been extensively investigated (Baffington \& Montgomery 1997). However, to the authors' knowledge there is no study on the influence of decelerating flow on incipient motion of gravel-bed channels. This kind of flow can be especially considered during low flows that water travels through a series of pool sections in gravel-bed rivers. Therefore, the primary objective of the present study is to investigate the effect of decelerating flow (velocity decreases in the stream-wise direction) on the incipient of motion of sediment. Since measurements of the Reynolds stress are difficult to make in the field, an attempt is made to present a simple alternative which can be easily applied to gravel-bed rivers. Finally, application of the Shields diagram to predict the incipient motion is investigated for decelerating flow over a gravel-bed channel. 


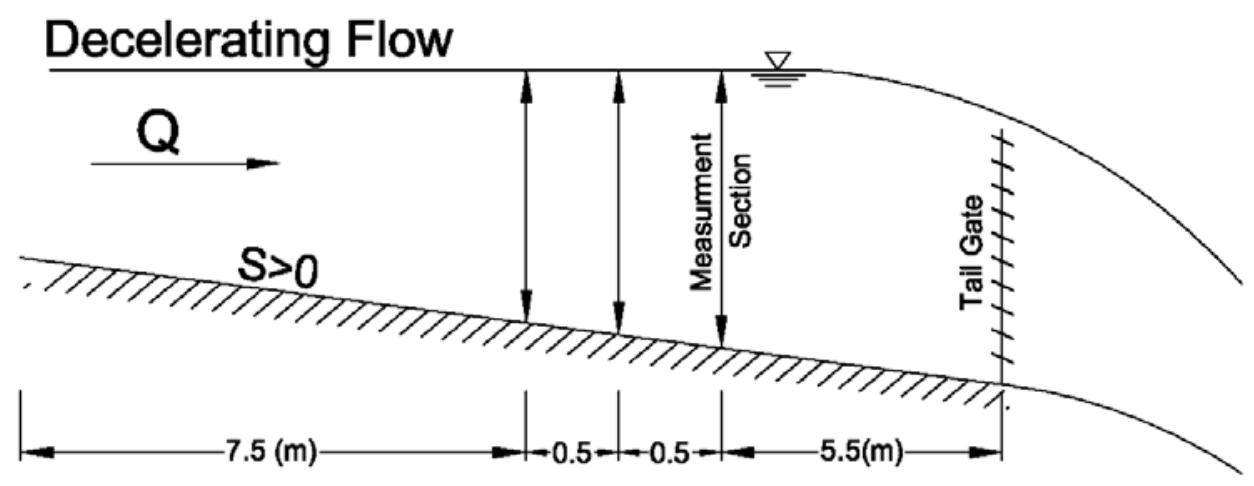

Figure 1. Sketch of experimental set-up for decelerating flow.

\section{Experimental set-up and procedure}

The tests were conducted in a $14 \mathrm{~m}$ long rectangular, glass-walled flume having $0.6 \mathrm{~m}$ width and $0.5 \mathrm{~m}$ depth. The slope of the flume was set to a horizontal position, with desired bed slopes developed by adjusting the sediment fill within the flume. There was an adjustable gate to keep the desired flow depth. To ensure the establishment of fully developed turbulent flow, the measuring reach was located downstream of the section where the upper limit of the boundary layer reaches the water surface.

Water depths are measured with a mobile point gage limnimeter. To verify that the flow is nonuniform, water depth is measured at three sections: $6.50,6.0$, and $5.50 \mathrm{~m}$ from the downstream end of flume (figure 1). The test section is located $5.50 \mathrm{~m}$ from the downstream end of the flume. Grid damps the oscillation observed within the head-box, which ensures stabilized flow conditions at the flume entrance. Subsequently, the flow passes over the gravelbed above the flume's measuring reach and drops at its downstream end into a collection tank linked to the sumps. Decelerating flow is tried to be reached by operating the downstream tail gate and positive channel slopes. Large (positive) values of channel slope, greater than its critical value were generally taken for decelerating flows. In decelerating flow, depth of flow increases towards downstream, therefore in a flume with a constant width, velocity decreases in flow direction. In this case, the longitudinal pressure gradient is positive $(\mathrm{d} p / \mathrm{d} x>0)$.

To obtain various bottom slopes; they were adjusted by varying the thickness of the gravel layer along the flume (minimum thickness of $50 \mathrm{~mm}$ ). Flow discharge was calculated from the discharge curve of the intermediate tank's weir. The experiments were conducted under steady non-uniform (decelerating flow condition) for two cases: fixed bed (eleven velocity profile) and mobile bed (nine velocity profiles). The reason of investigating the fixed bed case in this study is to compare the Reynolds stress distribution and Shields parameter values (non-critical values) with mobile bed case under decelerating flow. In fact only for mobile bed the incipient motion can be observed and no particle motion is considered for fixed bed channel. To achieve the mobile bed situation, the experiments were started with small flow discharge, at the condition of the bed observed. It was found that the materials comprising the bed were stationary for small discharges. Then, the flow discharge was increased to a certain value, and it was found that sediment particles just started moving. This condition is known as the condition of incipient motion of the sedimentary particles. In fact, in visual study which was adopted in this research, flow is typically increased gradually until grain observed to move from plan bed surface (Yalin \& Karahan 1979). Visual observation depends 
on investigator's definition of how much movement constitutes initial motion (Neill \& Yalin 1969, Wilcock 1988). In this study several grains motion was observed in measuring reach. However, it should be mentioned that theoretically the threshold should be defined as zero bed-load transport rate, but it is not meaningful in practical situation (Wu et al 2000). Many experiments show that even if the flow strength is much weaker than the critical condition proposed by Shields, there are still some sediment particles moving on the bed (e.g. Han \& He 1984). An acoustic Doppler velocimeter was used for velocity measurements. The correlation between signal-to-noise ratio (SNR) and signal amplitude were recorded in the ADV file for each probe beam. For accurate measurements, the correlation coefficient for each signal beam should have values between $70 \%$ and $100 \%$. Also, for measuring mean velocities, the signalto-noise ratio (SNR) should be 5 or higher. The WinADV program was used for filtering the data after measurements and other post-processing analyses. Data with average correlation coefficients lower or equal than $70 \%$ were excluded. A three-beam average of correlation was used for filtering. The range of sample time was set between 5 and $7 \mathrm{~min}$. The sample reporting rate $21 \mathrm{~Hz}$ was used, while the acoustic frequency was $10 \mathrm{MHz}$.

The tests were run for two different gravel sizes, a fixed bed with a median grain size of $d_{50}=16.7 \mathrm{~mm}$ and, a mobile bed with $d_{50}=8 \mathrm{~mm}$. There is no sediment motion for fixed bed case (profiles 1 to 11 in table 1 ) then the reported dimensionless shear stress $\left(\tau^{*}\right)$ is a non-critical value. The critical shear stress values for mobile bed were reported in second part of table 1 (profiles 12 to 20). As seen from table 1, the differences between non-critical and critical shear stresses are small. This is typical in gravel bedded channels (Parker et al 1982)

Table 1. Experimental data.

\begin{tabular}{|c|c|c|c|c|c|c|c|c|c|}
\hline $\begin{array}{l}\text { Profile } \\
\text { No. }\end{array}$ & $\begin{array}{c}Q \\
(\mathrm{~L} / \mathrm{s})\end{array}$ & $S_{o}$ & $\begin{array}{c}h \\
(\mathrm{~m})\end{array}$ & $\begin{array}{c}u_{m} \\
(\mathrm{~m} / \mathrm{s})\end{array}$ & $\mathrm{Fr}$ & $\mathrm{Re}$ & $\begin{array}{l}u_{* u w} \\
(\mathrm{~m} / \mathrm{s})\end{array}$ & $\begin{array}{c}u_{* P L M} \\
(\mathrm{~m} / \mathrm{s})\end{array}$ & $\begin{array}{c}\tau_{* u w} \\
\left(\mathrm{~N} / \mathrm{m}^{2}\right)\end{array}$ \\
\hline \multicolumn{10}{|c|}{ Fix Bed $\left(d_{50}=16.7 \mathrm{~mm}\right)$} \\
\hline 1 & 50 & $1 \cdot 5$ & $0 \cdot 2$ & $0 \cdot 563$ & $0 \cdot 4$ & 111841 & $0 \cdot 052$ & $0 \cdot 056$ & $0 \cdot 01$ \\
\hline 2 & 50 & $1 \cdot 5$ & $0 \cdot 19$ & $0 \cdot 589$ & 0.43 & 111103 & $0 \cdot 059$ & $0 \cdot 058$ & $0 \cdot 013$ \\
\hline 3 & 60 & $1 \cdot 5$ & $0 \cdot 2$ & 0.61 & 0.44 & 121168 & $0 \cdot 06$ & 0.061 & $0 \cdot 013$ \\
\hline 4 & 70 & $1 \cdot 5$ & $0 \cdot 2$ & 0.662 & 0.47 & 131386 & $0 \cdot 072$ & $0 \cdot 087$ & 0.019 \\
\hline 5 & 80 & $1 \cdot 5$ & $0 \cdot 2$ & 0.764 & 0.55 & 151722 & $0 \cdot 081$ & 0.089 & 0.024 \\
\hline 6 & 90 & $1 \cdot 5$ & $0 \cdot 2$ & $0 \cdot 875$ & $0 \cdot 62$ & 173843 & $0 \cdot 089$ & 0.099 & 0.029 \\
\hline 7 & 40 & 0.75 & $0 \cdot 22$ & $0 \cdot 34$ & $0 \cdot 23$ & 74194 & $0 \cdot 03$ & 0.035 & 0.003 \\
\hline 8 & 50 & 0.75 & $0 \cdot 21$ & $0 \cdot 451$ & $0 \cdot 32$ & 91793 & $0 \cdot 041$ & $0 \cdot 04$ & 0.006 \\
\hline 9 & 60 & 0.75 & $0 \cdot 17$ & 0.627 & 0.49 & 105857 & $0 \cdot 062$ & $0 \cdot 07$ & $0 \cdot 014$ \\
\hline 10 & 70 & 0.75 & $0 \cdot 19$ & 0.668 & 0.49 & 124787 & $0 \cdot 061$ & $0 \cdot 05$ & $0 \cdot 013$ \\
\hline 11 & 80 & 0.75 & $0 \cdot 2$ & 0.745 & 0.53 & 147886 & $0 \cdot 058$ & 0.068 & $0 \cdot 012$ \\
\hline \multicolumn{10}{|c|}{ Mobile Bed $\left(d_{50}=8 \mathrm{~mm}\right)$} \\
\hline 12 & 50 & 0.75 & $0 \cdot 13$ & 0.733 & $0 \cdot 65$ & 94645 & $0 \cdot 056$ & 0.052 & $0 \cdot 024$ \\
\hline 13 & 60 & 0.75 & $0 \cdot 14$ & 0.787 & $0 \cdot 68$ & 107867 & $0 \cdot 057$ & $0 \cdot 077$ & $0 \cdot 025$ \\
\hline 14 & 70 & 0.75 & $0 \cdot 15$ & $0 \cdot 817$ & $0 \cdot 67$ & 121753 & 0.057 & 0.055 & 0.025 \\
\hline 15 & 80 & 0.75 & $0 \cdot 17$ & 0.833 & 0.64 & 140597 & 0.055 & $0 \cdot 078$ & 0.023 \\
\hline 16 & 85 & 0.75 & $0 \cdot 19$ & $0 \cdot 86$ & 0.63 & 160489 & 0.05 & 0.057 & 0.019 \\
\hline 17 & 60 & $1 \cdot 5$ & $0 \cdot 17$ & 0.726 & 0.57 & 121192 & 0.059 & 0.052 & 0.027 \\
\hline 18 & 70 & $1 \cdot 5$ & $0 \cdot 18$ & 0.758 & 0.57 & 135581 & 0.054 & 0.067 & 0.023 \\
\hline 19 & 80 & $1 \cdot 5$ & $0 \cdot 2$ & 0.8 & 0.57 & 158936 & 0.05 & 0.06 & 0.02 \\
\hline 20 & 85 & $1 \cdot 5$ & $0 \cdot 21$ & 0.785 & 0.54 & 165997 & 0.061 & 0.058 & 0.029 \\
\hline
\end{tabular}



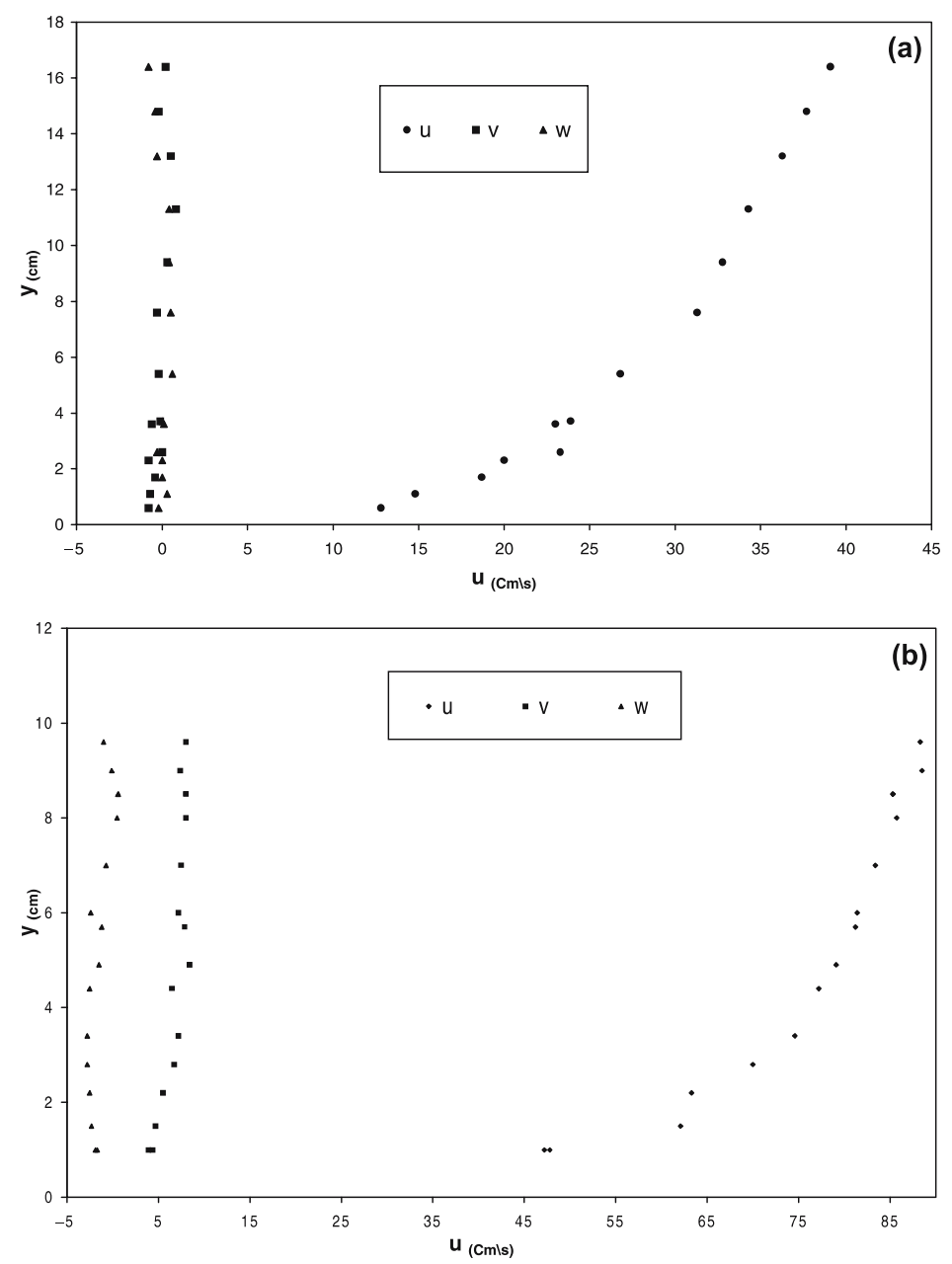

Figure 2. (a) Flow velocity distribution over fixed-bed channel; and (b) Flow velocity distribution over mobile bed channel.

because of approximately bankfull-threshold nature of bed mobility (Buffington 1995). The geometric standard deviation $\sigma_{g}$ of particle size distribution given by $\left(d_{84} d_{16}\right)^{0 \cdot 5}$ was less than 1.4 for the nearly-uniform sediments used in this study. The measuring cross section of velocity was situated on the distance of $8.5 \mathrm{~m}$ from flume entrance. The water depth, defined as the distance from the bed level to the water surface. The reference level can be found by trial-error in a way that the parabolic law reproduces adequately the measured velocity profile. Blinco \& Partheniades (1971) and Tu \& Graf (1992) obtained the reference level $0 \cdot 25 d_{50}$ under top of the particles. The position of the bed reference was determined $0.25 d_{50}$ under the top of gravel particles in this study. The adjustment of channel bed slope was carried out manually in such way that the thickness of gravel was $5 \mathrm{~cm}$ in channel downstream and its thickness in the upstream depended on the required slope. Considering the flow conditions, two slopes of $0.75 \%$ and $1.5 \%$ were selected for this study.

Velocity measurements were carried out in the middle part of flume and at least fourteen points velocity were taken for each profile. The measuring arrangement is that near the bed, 
the inner layer zone was approximately $y / h<0 \cdot 2$ (Afzalimehr \& Anctil 2001) where resolution of the measurement was $4 \mathrm{~mm}$ at 8 points and from there after it was $20 \mathrm{~mm}$. Figure 2 shows the flow velocity distributions over fixed and mobile beds. The shape of the profiles is similar to that observed by Kironoto \& Graf (1995) and Song \& Graf (1994) for decelerating flow over gravel-bed streams. However, the lateral and vertical components of velocity distribution differ more from one another for the mobile-bed case. This can be attributed to larger near-bed turbulent intensity for the mobile-bed stream. It should be stressed that Song \& Graf (1994) and Kirnoto \& Graf (1995) did not study the effect of decelerating flow on the incipient of motion, but they tried to investigate the influence of decelerating flow on the turbulent structure such as the turbulence intensities, eddy viscosity, mixing length and other turbulence characteristics. The experimental data are summarized in table 1 in which $Q=$ flow discharge (lit/s); $S_{o}=$ bottom slope, $h=$ flow depth $(\mathrm{m}) ; u_{m}=$ average flow velocity $(\mathrm{m} / \mathrm{s}) ; \mathrm{Fr}=$ Froude number defined by $u_{m} /(g h)^{0.5}$, and $\mathrm{Re}=$ Reynolds number that is $u_{m} h / v$.

\section{Bed shear stress estimation}

This quantity is defined as $\tau=\rho u_{*}^{2}$. Since $\rho$ is a constant for water, therefore with estimation of shear velocity $\left(u_{*}\right)$ the bed shear stress can be calculated. Several methods are available to estimate the bed shear stress of non-uniform flows, such as the Reynolds stress method (Kirnoto \& Graf 1995; Song \& Graf 1994), the parabolic law method (Afzalimehr \& Anctil 1999) and the log-law method (Afzalimehr \& Anctil 2001). In general, the log-law applies only for the data near-bed where considerable uncertainty exists in the measurement, such as the determination of the reference bed level, especially for gravel-beds (Afzalimehr \& Anctil 2000). On the other hand, the parabolic law is applied when the data are far from the bed and consequently less sensitive to the reference bed level and velocity measurement. The bed shear stress estimated using the Reynolds stress distribution is independent of the velocity measurements and the log-law hypothesis in which flow is in equilibrium. Here the flow equilibrium refers to a flow condition that does not depend on the upstream conditions and the velocity profiles and turbulent characteristics do not change along the flow direction. The parabolic law, in contrast to the log law may be applied even if equilibrium is not reached (Chen 1991). According to Barenblatt (1982), the parabolic law works as well as the log law, although it is often taken into account as purely empirical approach. Furthermore, the law of the wall does not hold even for high Reynolds number and is an approximate representation of measured data. Therefore, in this study, the law of the wall will not be applied for estimation of shear velocity.

The shear velocity is estimated using the parabolic law by the data of the outer layer and the following equation (Afzalimehr \& Anctil 1999):

$$
u_{* P L M}=\frac{\Omega u_{\max }}{\lambda}
$$

where $\Omega$ is the slope of the regression equation between $u / u_{\max }$ and $\left[1-\left(y+0 \cdot 25 d_{50} / h+\right.\right.$ $\left.\left.0 \cdot 25 d_{50}\right)\right]^{2} ; u$ is the mean point velocity at the distance $y$ measured from the reference level, $u_{\max }$ is the maximal velocity at the water surface; and $\lambda$ is a constant that depends on the deviation point of the outer layer from the inner layer $(x)$ in each velocity profile which is defined as follows (Afzalimehr \& Anctil 1999):

$$
\lambda=\frac{2 \cdot 5}{2 x(1-x)}
$$




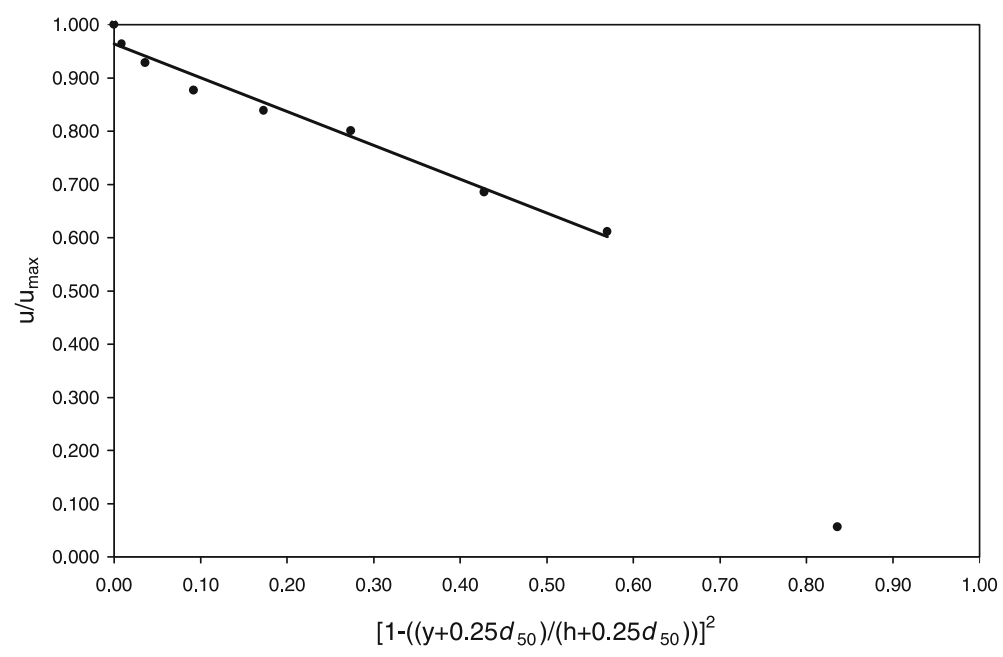

Figure 3. Fitness of the parabolic law to the outer layer data.

Afzalimehr \& Anctil (1999) showed that the parabolic law method fits nicely to the outer region data $(y / h>x)$ over a fixed-gravel-bed. Furthermore, figure 3 shows the fitness of the parabolic law method to the outer layer data $(y / h>x)$ for the mobile bed in this research.

To estimate shear velocity using the Reynolds stress, first the mean value of the Reynolds stress for each point is estimated as follows:

$$
\overline{u^{\prime} w^{\prime}}=\frac{1}{N} \sum_{i=1}^{i=N} u^{\prime} w^{\prime}
$$

where $u^{\prime}$ and $w^{\prime}$ are the root mean square values of the velocity fluctuations in the longitudinal and in the vertical directions and $N$ is the number of observations at each sample point (almost 7500 for this study). Then, by extrapolating, using a polynomial regression fit to the Reynolds stress profiles until the reference level, the corresponding intercept at $y=0$ is taken as bed shear stress $\left(\tau=\rho u_{*}^{2}\right)$. In this paper, the Reynolds stress method is applied to determine the Shields parameter.

\section{Results}

\subsection{Reynolds stress distribution}

The prediction of critical shear stress related to incipient motion is very important in hydraulics of sediment transport. In fact, the bed shear stress is pertinent to estimate the sediment threshold and bed load of sediments. Since the thickness of the layer, where the viscous shear stress is important, is small in comparison to the flow depth for flow over gravel-beds, the Reynolds stress can be estimated as the total shear stress $\tau=\rho \overline{u^{\prime} w^{\prime}}$.

In figure 4, the Reynolds stress profiles for decelerating flow over fixed and mobile beds are plotted against of $y$, where $y$ is the distance from the reference level of channel bed. Data 

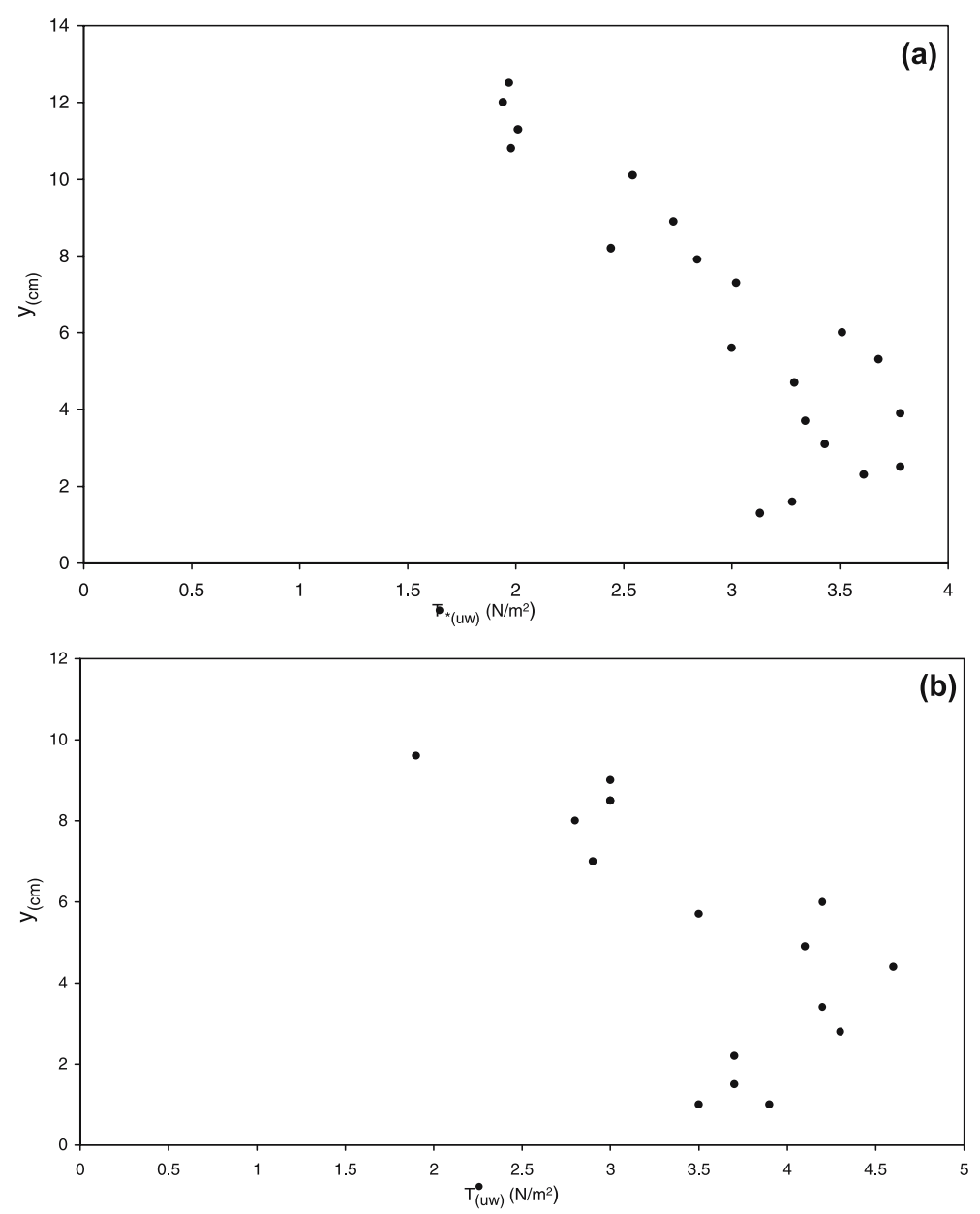

Figure 4. (a) Reynolds stress distribution over fixed-bed channel; and (b) Reynolds stress distribution over mobile bed channel.

scattering is pronounced in decelerating flow due to air bubbles appearing in the decelerating flow (Kironoto \& Graf 1995).

For decelerating flow over fixed and mobile beds, the Reynolds stress is maximal at a certain distance above the bed and decreases monotonically towards the water surface, therefore the profile shapes become convex. However, for the case of uniform flow with a specific depth, the Reynolds stress vanishes at the wall and decreases linearly with increasing distance from the wall (Song et al 1994). For decelerating flow, a convex distribution can be justified using the Navier-Stokes equation in which $\partial p / \partial x=\partial \tau / \partial y$ (Cousteix 1989). Since the longitudinal pressure gradient $(\partial p / \partial x)$ increases in the stream-wise direction for a decelerating flow, therefore vertical shear stress distribution $(\partial \tau / \partial y)$ has a positive sign that is an increase in $\tau$ near the bed (see figure 4). On the other hand, no specific pattern for $v^{\prime} w^{\prime}$ and $u^{\prime} v^{\prime}$ distributions exist in decelerating flow over fixed as well as mobile beds. In this case the distributions have tendency to be zero along the flow depth. 


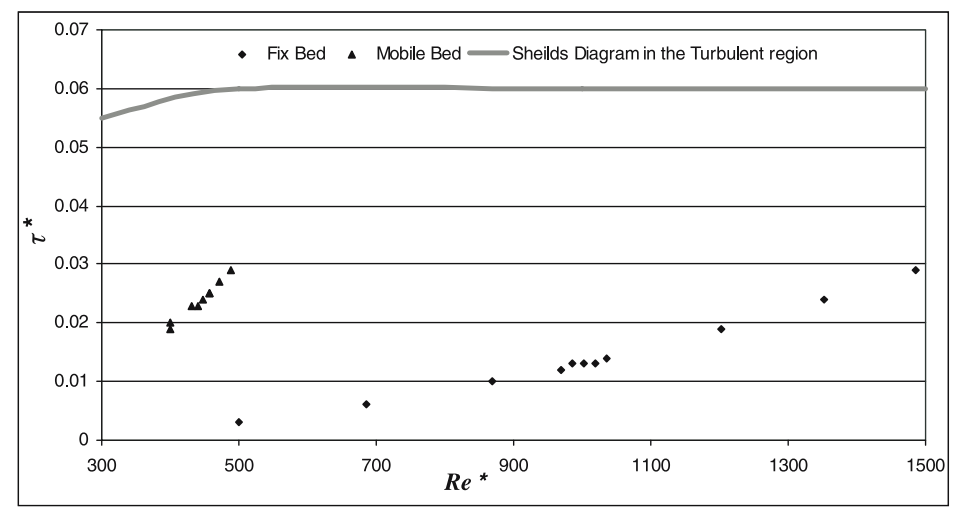

Figure 5. Comparison of the experimental data with the curve ( $\tau^{*}$ versus $\mathrm{Re}^{*}$ ) proposed by Shields in rough-turbulent regime.

\subsection{Shields parameter}

Shields' original data have evolved over time because of drafting errors and personal interpretations by later workers (Buffington 2000). In fact, the Shields diagram was obtained in a flume with fully developed turbulent flow, using sediment ranging in size from $0.4 \mathrm{~mm}$ to $3.4 \mathrm{~mm}$. A variety of bed forms and relative roughnesses were present during Shields' experiments (Baffington 2000). Because he did not account for the form drag caused by these roughness elements, values of dimensionless critical shear stress determined from stress-transport extrapolation may have been overestimated. The sediment used by Shields and his other data sources were not uniform in size and shape. This may also explain some of the scatter of dimensionless critical shear stress values reported by Shields.

The commonly quoted value of $\tau_{* c}=0.06$ for rough turbulent flow reflects a single data point within the overall swath of Shields data (1936). According to Neill (1968), this large value of $\tau_{* c}$ can be due to some non-uniformity in sediments used in laboratory studies and also due to the fact that the same probability of movement may not have existed at the critical condition for different sediment sizes. In addition, it should be noticed that reported value $\tau_{* c}=0.06$ in literature generally predicts high stresses that likely represent instantaneous rather than time averaged critical shear stress (Buffington et al 1992).

Figure 5 shows the functional relationship between $\tau_{*}$ and $\operatorname{Re}_{*}$ for the 20 data in this study and suggested diagram by Rouse (1949) and other investigators (Buffington \& Montgomery 1997; Shvidchenko \& Pender 2000) on flumes with a flat bed in the turbulent region of large Reynolds number $\mathrm{Re}_{*}>300$. In fact, Rouse (1949) promoted Shields' work by fitting a line through the data. Rouse fit of the data diverges toward the upper envelop at higher critical boundary Reynolds number values, approaching $\tau^{*} c=0.06$ at $\operatorname{Re}^{*}>500$.

Examination of the computed Shields parameters for each of the nine velocity profiles measured over the mobile-bed stream indicates that all the data lie under the Shields curve in figure 5. This is due to convex form of the Reynolds stress distribution for decelerating flow which has smaller bed shear stress than that reported in literature for uniform flow. In addition, the values of less than $\tau_{* c}=0.03$ for nine velocity profiles measured over the mobile bed shows that the experiments were conducted for weakly mobile bed condition, as mentioned by Nikora \& Goring (2000). For example in profiles 16 and 19 of table 1, the Shields parameters are less than minimum value of incipient motion that is 0.02 (Konrad et al 
2002) for gravel-bed streams. However, in the both velocity profiles (16 and 19), movement of particles was observed. This result is in agreement with above explanation that in decelearting flow the critical shear stress has smaller values than that reported for uniform flow condition. Therefore, it seems that there is no universal value for $\tau_{* c}$ in rough turbulent flow in open channels as mentioned by Buffington and Montgomery (1997). Although, it may consider a range for $\tau_{* c}$ which depends on experiment conditions.

In the turbulent region of large particle Reynolds numbers $\left(\operatorname{Re}_{*}>300\right)$, the laminar sublayer is interrupted by the particle size. As seen in figure 5, for the hydraulically rough boundary, the Shields diagram shows a constant value of 0.06 being independent of the particle Reynolds number $\mathrm{Re}_{*}$. However, the results of this study (solid triangles on figure 5) indicate that for $\tau_{* c}=0.02$ which is under the Shields curve, the bed was mobile and movement of particles was observed. This underestimation in Shields diagram reflect a variety of factors such as different in bed material properties (i.e. shape, rounding) neglect of roughness elements (size), method of shear stress determination, sampling technique used to estimate grain size distribution and difference in flow properties arising from changes in bed roughness and channel gradient as reported by Ashida \& Bayazitt 1973, Bathurst et al 1987, Graf 1991. Likewise, incipient motion of non-spherical particles is affected by their orientation with respect of to the down stream flow direction (Carling et al 1992). Platy grains used in this study tend to have low incipient motion thresholds as mentioned by Mantz (1977). Also, the methods used to calculate shear stress can affect the Shields parameter. In some investigations shear stress is determined as a simple depth-slope product (e.g. Powell \& Ashworth 1995), while in other research bed shear stress is estimated from velocity profile (e.g. Nezu \& Nakagawa 1993). These methods can result in different estimate of shear stress and the Shields parameter particularly for non-uniform flow condition through a study reach (Afzalimehr \& Anctil 1999). Therefore, to obtain more realistic insight for calculation of shear stress and thus the critical Shields parameter values, it is vital to analyse the shear stress distribution for nonuniform flow. Therefore, an important explanation is related to the effect of flow structure on incipient motion. In fact, this study shows that when there is a positive pressure gradient in flow direction of a reach (decelerating flow), the Shields parameter is smaller than that proposed by Shields for zero pressure gradient (uniform flow). The decelerating flow influence is presented by convex shear stress distribution in which near the bed, critical shear stress is smaller than the critical value of linear shear stress distribution for uniform flow, as reported in original Shields diagram. Likewise, the Task Committee on preparation of sedimentation manual (1966) and Neill (1968) had already observed that $\tau_{* c}=0.06$ in completely rough boundary is on the high side and true critical condition may occur at lesser value that is $\tau_{* c}=0.06$. Therefore, one can state that the experimental data are in complete disagreement with the Shields diagram, which is not at all uncommon for gravel-beds, as it was reported in the literature (Andrews \& Kuhnle 1993, Dey \& Raju 2002).

\section{Discussion}

Shear velocity estimation using two approaches is presented in the table 1. Also, figure 6 shows that the estimated shear velocity by the parabolic law method $\left(u_{* P L M}\right)$ and the Reynolds stress method $\left(u_{* u w}\right)$ are comparable. However, there are some exceptions, such as profiles 13 and 15 over the mobile-bed streams. In figure 6 , the middle line is the line of perfect agreement and the two other lines show $\pm 25 \%$ of deviation from the line of perfect agreement. The similarity of the two approaches indicates that the PLM method can be used to simplify 


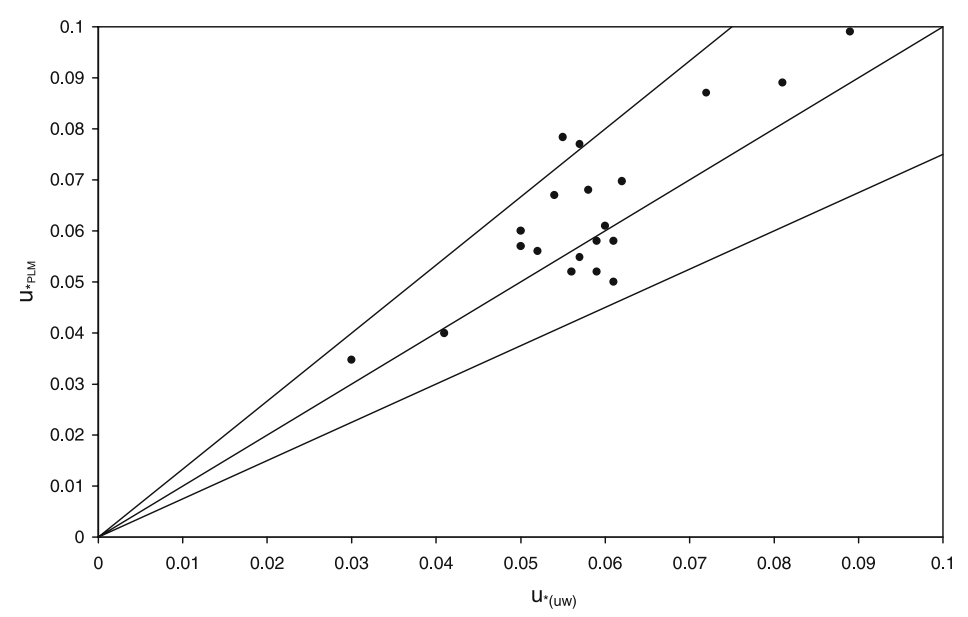

Figure 6. Comparison of calculated shear velocity from the Reynolds stress and the parabolic methods.

field measurements. It should be mentioned that the parabolic law method can be applied for one-dimentional flows using the outer region data of mean velocity profiles. However, the Reynolds stress method needs to calculate the root mean square values of velocity fluctuations in longitudinal and vertical directions. Also, the parabolic law method can be applied with simple instruments such as a currentmeter, while the Reynolds stress method requires the advanced measuring equipment such as ADV.

According to Yalin \& Karahan (1979) for a rough turbulent flow, where the size of the largest macro turbulent eddies is comparable with flow depth, these eddies have some influence on the critical stage. As a result, some investigators claim that relative flow depth $h / d_{50}$ should be considered as the additional variable for estimating $\tau_{* c}$ and that the removable scatter in the Shields diagram may be due to the omission of the relative flow depth. However, the results of this study do not indicate any correlation between $\tau_{*}$ and the relative depth $h / d_{50}$. For example, for the largest relative flow depth over the fixed-bed stream (profile 6 in table 1) with $S_{o}=1.5 \%, Q=0.09 \mathrm{~m}^{3} / \mathrm{s}$, and $u_{m}=0.875 \mathrm{~m} / \mathrm{s}$, particle motion was not observed, then $\tau_{*}=0.029$ is a non-critical value. It should be noticed that for the profile $6, d_{50}=16.7 \mathrm{~mm}$ therefore, the resistance to motion in the profile 6 is large.

This analysis indicates that less emphasis should be given on choosing a universal $\tau_{* c}$ values for of fully turbulent flow and high relative flow depth typical of gravel-beds as mentioned by Buffington and Montgomerey (1997). It is necessary to give more emphasis on flow structure (decelerating or uniform) and choosing defendable values for particular application, given the observed methodological biases, uses of each approach and systematic influence of sources of uncertainty associated with different methods and experimental conditions.

\section{Conclusions}

Experiments were conducted to determine the effect of decelerating flow on the incipient motion of a gravel-bed channel. The results show that:

(i) The Reynolds stress distribution over fixed and mobile beds has a convex form. Due to this form, $\tau_{* c}$ value for decelerating flow is less than the reported values in literature. 
(ii) The parabolic law method presents a good agreement with the Reynolds stress method for calculating the shear velocity.

(iii) The Shields diagram overestimates $\tau_{* c}$ for decelerating flow condition.

(iv) There is no correlation between $\tau_{* c}$ and the relative flow depth for decelerating flow over a gravel-bed channel.

(v) More emphasis should be given in selecting defendable values of $\tau_{* c}$ for particular application with considering the flow structure.

The authors gratefully acknowledge Dr John M Buffington of Idaho University for providing helpful comments on earlier draft of this paper.

\section{List of symbols}

$d_{16} \quad 16 \%$ finer particle diameter;

$d_{50} \quad$ Median diameter of sediment particles;

$d_{84} \quad 84 \%$ finer particle diameter;

Fr $\quad$ Froude number defined by $u_{m} /(g h)^{0 \cdot 5}$;

$g \quad$ Gravitational acceleration;

$h \quad$ Flow depth;

$h / d_{50} \quad$ Relative flow depth;

$k_{s} \quad$ Nikuradse's equivalent roughness;

$N \quad$ Number of observations at each sample point;

$Q \quad$ Flow discharge;

Re Reynolds number that is $u_{m} h / v$;

$\mathrm{Re}_{*} \quad$ Particle Reynolds number $u_{*} d_{50} / v$;

$S$ ○ Bottom slope;

$u \quad$ Mean point velocity at the distance $y$ measured from the reference level;

$u^{\prime} \quad$ Root mean square value of the velocity fluctuations in the longitudinal direction;

$u_{m} \quad$ Average flow velocity;

$u_{\max } \quad$ Maximum point velocity at the distance $y$ measured from the reference level;

$u_{*} \quad$ Shear velocity;

$u_{* c} \quad$ Critical shear velocity;

$u_{* P L M} \quad$ Shear velocity estimated by the parabolic law method;

$u_{* u w} \quad$ Shear velocity estimated by the Reynolds stress method;

$\overline{u^{\prime} w^{\prime}} \quad$ Mean value of the Reynolds stress for each point;

$v^{\prime} \quad$ Root mean square value of the velocity fluctuations normal to the longitudinal direction;

$w^{\prime} \quad$ Root mean square value of the velocity fluctuations in the vertical direction;

$x \quad$ Deviation point of the inner layer from the outer layer;

$y \quad$ Distance from the reference level of channel bed;

$\gamma \quad$ Specific weight of water;

$\gamma_{s} \quad$ Specific weight of sediment;

$\lambda$ A constant in the parabolic law method;

$v \quad$ Kinematic viscosity;

$\rho \quad$ Mass density of water; 
$\sigma_{g} \quad$ Geometric standard deviation; $\left(d_{84} / d_{16}\right)^{0 \cdot 5}$;

$\tau \quad$ Total shear stress $\tau=\rho \overline{u^{\prime} w^{\prime}}$;

$\tau_{* c} \quad$ Critical Shields parameter;

$\tau_{c} \quad$ Critical bed shear stress;

$\Omega \quad$ Slope of regression equation between $u / u_{\max }$ and $\left[1-\left(y+0 \cdot 25 d_{50} / h+0 \cdot 25 d_{50}\right)\right]^{2}$.

\section{References}

Afzalimehr H, Anctil F 1999 Velocity distribution and shear velocity behaviour of decelerating flows over a gravel-bed. Can. J. Civil Eng. 26: 468-475

Afzalimehr H, Anctil F 2000 Accelerating shear velocity in gravel-bed channels. Hydrol. Sci. J. 45: $113-124$

Afzalimehr H, Anctil F 2001 Vitesse de frottement associee a un ecoulement non-uniforme et une rugosite relative intermediaire. J. Hydraul. Res. 39: 181-186

Andrews E D 1994 Marginal bed load transport in a gravel-bed stream, Sagehen Creek, California. Water Resour. Res. 30: 2241-2250

Andrews E D, Kuhnle R A 1993 Incipient motion of sand-gravel sediment mixture. J. Hydraul. Eng. 119: $1400-1415$

Andrews E D, Parker G 1987 Formation of a coarse surface layer as the response to gravel mobility. Sediment transport in gravel-bed rivers, (eds) C R Thorne, J C Bathurst, R D Hey (Chichester: Wiley) 269-325

Ashida K, Bayazit M 1973 Initiation of motion and roughness of flows in steep channels. Proc. $15^{\text {th }}$ Congr. Int. Assoc. Hydraul. Res. 1: 475-484

Barenblatt G I 1982 Similarity, self-similarity and intermediate asymptotics, (Dordrecht, Netherlands: Kluwer Academic)

Bathurst J C, Graf W H, Cao H H 1987 Bed load discharge equations for steep mountain rivers. Sediment transport in gravel-bed rivers, (eds) C R Thorne, J C Bathurst, R D Hey (Chichester: Wiley) 453-491

Blinco P H, Partheniades E 1971 Turbulence characteristics in free surface flows over smooth and rough boundaries. J. Hydraul. Res. 9: 43-69

Buffington J M, Dietrich W E, Kirchner J W 1992 Friction angle measurements on naturally formed gravel streambed: Implications for critical boundary shear stress. Water Resour. Res. 28: 411-425

Buffington J M 1995 Effects of hydraulic roughness and sediment supply on surface textures of gravelbedded rivers. M S thesis, $184 \mathrm{pp}$. Univ. of Wash. Seattle (USA)

Buffington J M, Montgomery D R 1997 A systematic analysis of eight decades of incipient motion studies with special reference to gravel-bedded rivers. Water Resour. Res. 33: 1993-2029

Buffington J M 2000 The legend of A. F. Shields (Closure). J. Hydraul. Eng. 126: 721-723

Carling P A, Kelsey A, Glaister M S 1992 Effect of bed roughness, particle shape and orientation on initial motion criteria. Dynamics of gravel-bed rivers, (eds) P Billi, R D Hey, C R Thorne, P Tacconi (New York: Wiley) 24-39

Chen C L 1991 Unified theory on power laws for flow resistance. J. Hydraul. Eng. 117: 371-389

Chiew Y M, Parker G 1994 Incipient sediment motion on non-horizontal slopes. J. Hydraul. Res. 32: 649-660

Church M, Hassan M A, Wolcott J F 1998 Stabilizing self-organized structures in gravel-bed streams. Water Resour. Res. 34: 3169-3179

Cousteix J 1989 Aerodynamique turbulence et couche limite, CEPADUES-editions, Toulouse, France $627 \mathrm{p}$

Dey S 1999 Sediment threshold. Appl. Math. Modelling 23: 399-417

Dey S, Debnath K 2000 Influence of stream-wise bed slope on sediment threshold under stream flow. J. Irrig. Drain. Eng. 126: 255-263

Dey S, Raju U 2002 Incipient motion of gravel and coal beds. Sādhanā 27: 559-568 
Fernandez Luque R, Van Beek R 1976 Erosion and transport of bed load sediment. J. Hydraul. Res. 14: $127-144$

Garde R J, Ranga Raju 1985 Mechanics of sediment transportation and alluvial stream problems. 2nd ed. (New York: Wiley)

Graf W H 1991 Flow resistance over a gravel-bed: Its consequence on initial sediment movement. Fluvial Hydraulics of Mountain Regions, Lect. Notes Earth Sci. Ser. 37 (eds) A Armanini, G DiSilvio (New York: Springer) 17-32

Han Q W, He M M 1984 Stochastic theory of sediment movement, (Beijing: Science Press) (in Chinese)

Ikeda S 1982 Incipient motion of sand particles on side slopes. J. Hydraul. Eng. 108: 95-114

Iwagaki Y 1956 Fundamental study on critical tractive force. Trans. Jpn. Soc. Civil Eng. 41: 1-21

Kironoto B A, Graf W H 1995 Turbulence characteristics in rough non-uniform open channel flow. Proc. of the Institution of Civil Eng., Water, Maritime and Energy 112: 336-348

Konrad C P, Booth D B, Burges S J, Montgomery D R 2002 Partial entrainment of gravel bars during floods. Water Resour. Res. 38: 1104-1120

Lavelle J W, Mofjeld H O 1987 Do critical stresses for incipient motion and erosion really exist? J. Hydraul. Eng. 113: 370-385

Mantz P A 1977 Incipient transport of fine grains and flanks by fluids-extended Shields diagram. J. Hydraul. Div. 103: 601-615

Miller M C, McCave I N, Komar PD 1977 Threshold of sediment motion under unidirectional currents. Sedimentology 24: 507-527

Mizuyama T 1977 Bedload transport in steep channels. Unpub. Ph D dissertation, Kyoto University, Kyoto, Japan, 118 pp

Mueller E R, Pitlick J, Nelson J M 2005 Variation in the reference Shields stress for bed load transport in gravel-bed streams and rivers. Water Resour. Res. 41: W04006, (doi: 10·1029/2004WR003692)

Nezu I, Nakagawa H 1993 Turbulence in open-channel flows, IAHR Monograph Series (Rotterdam: Balkema Publisher)

Neill C R 1968 A re-examination of the beginning of movement for coarse granular bed materials. Report No. 68, Hydraul. Res. station, Wallingford, England

Neill C R, Yalin M S 1969 Quantitative definition of beginning of bed movement. J. Hydraul. Div., Am. Soc. Civil Eng. 95: 585-588

Nikora V, Goring D 2000 Flow turbulence over fixed and weakly mobile gravel-beds. J. Hydraul. Eng. 126: 679-690

Parker G, Klingeman P C, McLean D G 1982 Bed load and size distribution in paved gravel-bed streams. J. Hydraul. Div. 108: 544-571

Patel P L, Ranga Raju K G 1999 Critical tractive stress of nonuniform sediments. J. Hydraul. Res. 37: $39-58$

Powell M, P J Ashworth 1995 Spatial pattern of flow competence and bed load transport in a divided gravel-bed river. Water Resour. Res. 31: 741-752

Rouse H 1949 Engineering Hydraulics, (New York: Wiley)

Shields A 1936 Application of similarity principles and turbulence research to bed-load movement. Hydrodynamics laboratory publications No. 167, W P Ott, J C Van Uchelen, Trans., U.S. Dept. of Agr., Soil Conservation Service Cooperative laboratory, California Institute of Technology, Pasadena, Calif.

Shvidchenko A B, Pender G 2000 Flume study of the effect of relative depth on the incipient motion of coarse uniform sediments. Water Resour. Res. 36: 619-628

Song T, Graf W H, Lemmin U 1994 Uniform flow in open channels with moveable gravel-bed. J. Hydraul. Res. 32: 861-876

Song T, Graf W H 1994 Non-uniform open channel flow over a rough bed. J. Hydroscience and Hydraul. Eng. 12: 1-25

Task Committee on preparation of sedimentation manual 1966 Sediment transportation mechanics: Initiation of motion. J. Hydraul. Eng., Am. Soc. Civil Eng. 92: 291-314 
Tu H, Graf W H 1992 Velocity distribution in unsteady open-channel flow over gravel-beds. J. Hydroscience and Hydraul. Eng. 10: 11-25

Wiberg P L, Smith J D 1987 Calculations of the critical shear stress for motion of uniform and heterogeneous sediments. Water Resour. Res. 23: 1471-1480

Wilcock P R 1988 Methods for estimating the critical shear stress of individual fractions in mixed-size sediment. Water Resour. Res. 24: 1127-1135

Wilcock P R 1992 Flow competence: A criticism of a classic concept. Earth Surf. Processes Landforms. 17: 289-298

Wu w, Wang S S Y, Jia Y 2000 Non-uniform sediment transport in alluvial rivers. J. Hydraul. Res. 38: 427-434

Yalin M S, Karahan E 1979 Incipient of sediment transport. J. Hydraul. Eng., Am. Soc. Civil Eng. 105: 1433-1443 